\title{
KNOWLEDGE, ATTITUDE AND PRACTICE OF BREASTFEEDING AMONG WORKING AND NON-WORKING MOTHERS IN SAUDI ARABIA
}

\author{
By \\ Elmougy $\mathrm{AM}^{1}$, Matter $\mathrm{MK}^{1}$, Shalaby $\mathrm{NM}^{1}$, El-Regal $\mathrm{ME}^{1}$, Abu Ali $\mathrm{WH}^{2}$, \\ Aldossary $\mathrm{SS}^{3}$, Elsherbeny $\mathrm{EE}^{4}$ and El-Saed $\mathrm{A}^{4}$ \\ ${ }^{1}$ Department of Pediatric, Mansoura university children Hospital, ${ }^{4}$ Department of Public Health and \\ Community Medicine, Faculty of Medicine, Mansoura University, Mansoura, Egypt, ${ }^{2}$ Department of \\ Pediatric, King Fahad University Hospital, \\ Medical College, Dammam University, Dammam, \\ ${ }^{3}$ Department of Pediatric, Saad Specialist Hospital, Alkhobar, Saudi Arabia.
}

\begin{abstract}
Introduction: Saudi Arabia has experienced major socioeconomic changes over the last 3 decades that potentially promote women employment. The impact of working status on the mother's awareness and practices of breastfeeding has never been the focus of previous local studies. Aim of work: to examine the awareness and practices of breastfeeding among working and non-working mothers in two centers in the Eastern region of Saudi Arabia. Materials and methods: A cross-sectional study was carried out among mothers attending the Maternal and Child Health (MCH) clinics at Saad Specialist Hospital, and at King Fahad University Hospital from January to April 2015. Data were collected during an interview that covered demographic characteristics of the mothers, as well as Knowledge, Attitude, and Practice of breastfeeding. Results: A total 280 mothers (136 working and 144 non-working; 245 Saudi and 35 non-Saudi) were included in the study. The age ranged from 18 to 55 years with a mean of $29.9 \pm 8.0$ years. The overall awareness of breastfeeding benefits and duration was $78.1 \%$, with no significant difference between working and non-working mothers $(79.3 \%$ versus $76.9 \%, \mathrm{p}=0.195$ ). Approximately $97.5 \%$ of the studied mothers initiated breastfeeding while $45.7 \%$ had exclusive breastfeeding for at least 6 months, with no significant differences by working status $(\mathrm{p}=0.716$ and $\mathrm{p}=1.000$, respectively). Several reasons for early stopping of exclusive breastfeeding were reported. Conclusion: Among mothers attending $\mathrm{MCH}$ services in two centers in the Eastern region, there was high
\end{abstract}


awareness and better practices of breastfeeding than reported before, with no significant differences between working and non-working mothers .

Keywords: Breastfeeding, Knowledge, Practices, Saudi, Working mothers and Non working mothers.

\section{Introduction}

Breastfeeding (or nursing) is the process of feeding human breast milk to an infant, either directly from the breast or by expressing (pumping out) the milk from the breast and bottle-feeding it to the infant (National Institute of Child Health and Human Development, 2009). The World Health Organization (WHO), United Nations Children's Emergency Fund (UNICEF), and the American Academy of Pediatrics recommend that breastfeeding should begin within the first hour of a baby's life and should be exclusive for the first six months of life ( American Academy of Pediatrics, 2012 and WHO, 2016). Thereafter, breastfeeding should continue along with complementary foods until two years of age (Kramer and Kakuma, 2012). To promote breastfeeding, the WHO and the UNICEF developed a Baby Friendly Hospital Initiative (BFHI) in 1991, which was then adopted by 20.000 hospitals in 156 countries all over the world, including Saudi Arabia (WHO, 2009).
Globally, it was estimated that nearly 820,000 deaths per year among children below five years could be avoided through more widespread breastfeeding (Victira et al., 2016). Breastfeeding is beneficial for both the baby and the mother. It was shown to reduce the risk of respiratory tract infections and diarrhea (American Academy of Pediatrics, 2012). Longterm baby benefits include lower risks of asthma, food allergies, inflammatory bowel disease, diabetes, obesity and leukemia (American Academy of Pediatrics, 2012). Additionally, prolonged and exclusive breastfeeding can improve children's cognitive development (Kramer et al., 2008). Advantages of breastfeeding for the mother include reducing the risk of post-partum bleeding and depression and helping weight loss and spacing pregnancies (UNICEF and WHO, 2015). Long-term benefits may include a low risk of developing breast cancer, rheumatoid arthritis, and cardiovascular disease (Victira et 
al., 2016). From the economic point of view, breastfeeding is obviously less expensive than infant formulas ( American Academy of Pediatrics, 2012).

In Saudi Arabia, a number of studies showed high (above 90\%) rates of initiation of breastfeeding but very low rates of exclusive breastfeeding at 6-month age (El Mouzan et al., 2009 and Al Juaid et al., 2014 ). The negative impactofmother's workonbreastfeeding is well known internationally ( Ong et al., 2005 and Iellamo et al., 2015 ). Several initiatives and strategies have been suggested to improve the rates of breastfeeding among working mothers (Johnston and Esposito, 2007; Hirani and Karmaliani, 2013 and Atabay et al., 2015). Saudi Arabia has experienced major socioeconomic changes over the last 3 decades that are believed to affect women's belief and practices regarding breastfeeding (Nabi and Al-Mendalawi, 2008). Although still suboptimal, the International Labor Organization showed that the percentage of Saudi women engaged in the labor market has markedly increased over the last 2-3 decades (ILO, 2016). The impact of working status on the mother's awareness and practices of breastfeeding has never been the focus of previous studies in Saudi Arabia. However, a number of studies examined the mother's working status among other predictors of breastfeeding intention and practices (Kordyet al.,1992; AlMadani et al., 2010 and El-Gilany et al., 2011).

\section{Aim of work}

The aim of the current study was to examine the awareness and practices of breastfeeding among working and nonworking mothers in two centers in the Eastern region of Saudi Arabia.

\section{Materials and methods}

Study design: A cross-sectional study design.

\section{Place and duration of the study:} The study was carried out in the Eastern region of Saudi Arabia among mothers attending the Maternal and Child Health $(\mathrm{MCH})$ clinics in two major hospitals: Saad Specialist Hospital in Alkhobar, and King Fahad University Hospital in Dammam, from January to April 2015.

Study sample: The target population was mothers aged between 
18 and 55 years, irrespective of nationality and working status. The exclusion criteria included mothers below 18 years old or mothers who had a child with congenital malformation that may affect the success of breastfeeding practice. Out of 352 mothers, 306 agreed to join the study with a response rate of $86.9 \%$. Out of 306 mothers who joined the study, 26 questionnaires were incomplete and were excluded. The current study analyzed the data of the remaining 280 questionnaires.

Study methods: The data of the current study were collected during an interview carried out by a health educator nurse. A structured easily understood Arabic questionnaire was prepared by experts in child nutrition, pediatrics, and community medicine from the two included hospitals and was used to collect the data. The questionnaire included questions that covered (1) demographic characteristics of the target mothers such as age, nationality, education level, and working status; (2) obstetric history such as number of pregnancies and number and type of deliveries; (3) knowledge and awareness of breastfeeding such as sources of knowledge, health education, benefits of breastfeeding, weaning time, best method of feeding, and encouragement by health care providers such as gynecology and pediatrics doctors; (4) attitude towards breastfeeding; and (5) the possible causes of early stopping breastfeeding.

Study definitions: The following definitions adopted by WHO were used in the current study (WHO , 2008): Exclusive breastfeeding was defined as "breast milk is the only food received by the baby with no other liquids, not even water, or foods except for minerals or medicines "; and Any breastfeeding was defined as" receiving breast milk with any food or liquids including nonhuman milk or formula “.

\section{Consent}

A written consent was taken from the targeted mothers before participation in the study.

\section{Ethical approval}

The study was approved by the Research and Ethics Committees of both Saad Specialist Hospital and King Fahad University Hospital. Also, it was approved by IRB (Institutional Review 
Board) of the Faculty of Medicine, questions were reversed before scoring. Mansoura University.

\section{Data management}

Data were presented as means and standard deviations (SD) for continuous variables (such as age) and frequency and percentages for categorical variables (such as exclusive breastfeeding). The responses to Knowledge/Attitude (awareness) questions were Likertscaled and were scored between 1 (strongly disagree) and 5 (strongly agree). Overall awareness score was calculated by summing up the scores of all 8 awareness questions. Negatively stated Knowledge/Attitude Differences between working and nonworking mothers were tested using chi-square or Fisher's exact tests, as appropriate, for categorical data, and t-test was used for continuous data. Additionally, odds ratios of the factors associated with non-exclusive breastfeeding were calculated using univariate and multivariate logistic regression. Multivariate analysis was done backward stepwise logistic regression. All $\mathrm{p}$ values were twotailed. $\mathrm{p}$ value $<0.05$ was considered as significant. SPSS software (release 20.0, Armonk, NY: IBM Corp) was used for all statistical analyses. 


\section{Results}

Table 1: Socio-demographic characteristics and obstetric history of the study participants by working status.

\begin{tabular}{|c|c|c|c|c|}
\hline Variables & $\begin{array}{l}\text { Working } \\
\text { No=136 } \\
(48.6 \%)\end{array}$ & $\begin{array}{c}\text { Non-working } \\
\text { No=144 } \\
(51.4 \%)\end{array}$ & $\begin{array}{c}\text { Total } \\
\text { No=280 } \\
(\mathbf{1 0 0 \% )}\end{array}$ & p value\# \\
\hline \multicolumn{5}{|l|}{ Age (years) } \\
\hline Range & $20-52$ & $18-55$ & $18-55$ & \\
\hline Mean $\pm \mathrm{SD}$ & $32.4 \pm 7.2$ & $27.6 \pm 8.1$ & $29.9 \pm 8.0$ & $<0.001 * *$ \\
\hline $18-25$ & $21(15.9 \%)$ & $82(56.9 \%)$ & $103(37.3 \%)$ & $<0.001 * *$ \\
\hline $26-35$ & $71(53.8 \%)$ & $34(23.6 \%)$ & $105(38.0 \%)$ & \\
\hline$>35$ & $40(30.3 \%)$ & $28(19.4 \%)$ & $68(24.6 \%)$ & \\
\hline \multicolumn{5}{|l|}{ Nationality } \\
\hline Saudi & $112(82.4 \%)$ & $133(92.4 \%)$ & $245(87.5 \%)$ & $<0.05 *$ \\
\hline Non-Saudi & $24(17.6 \%)$ & $11(7.6 \%)$ & $35(12.5 \%)$ & \\
\hline \multicolumn{5}{|l|}{ Education } \\
\hline High school or less & $23(16.9 \%)$ & $77(53.5 \%)$ & $100(35.7 \%)$ & $<0.001 * *$ \\
\hline University & $113(83.1 \%)$ & $67(46.5 \%)$ & $180(64.3 \%)$ & \\
\hline \multicolumn{5}{|l|}{ Gravidity } \\
\hline$<3$ & $63(46.3 \%)$ & $103(71.5 \%)$ & $166(59.3 \%)$ & $<0.001 * *$ \\
\hline$\geq 3$ & $73(53.7 \%)$ & $41(28.5 \%)$ & $114(40.7 \%)$ & \\
\hline \multicolumn{5}{|l|}{ Parity } \\
\hline$<3$ & $67(49.3 \%)$ & $104(72.2 \%)$ & $171(61.1 \%)$ & $<0.001 * *$ \\
\hline$\geq 3$ & $69(50.7 \%)$ & $40(27.8 \%)$ & $109(38.9 \%)$ & \\
\hline \multicolumn{5}{|l|}{ Mode of delivery } \\
\hline Normal vaginal & $107(78.7 \%)$ & $122(84.7 \%)$ & $229(81.8 \%)$ & $>0.05$ \\
\hline Cesarean section & $29(21.3 \%)$ & $22(15.3 \%)$ & $51(18.2 \%)$ & \\
\hline
\end{tabular}

\# p: value was calculated using Chi-square, except age mean using t-test.

*: Significant $\quad * *$ : Highly significant 
Table 1 showed that the age of the participants ranged between 18 and 55 years with an average of $29.9 \pm 8.0$ years. Almost half $(48.6 \%)$ of the participants were working. The majority of the participants was Saudi $(87.5 \%)$ and had University education $(64.3 \%)$. Almost $60 \%$ of the participants reported gravidity and parity less than 3 , with the majority of them $(84.7 \%)$ having normal vaginal delivery. Compared with non-working mothers, working mothers were more likely to be older, non-Saudi, had University education, and having higher gravidity and parity.

Regarding prevalence of exclusive breastfeeding initiation and for at least 6 months by working status, approximately $97.5 \%$ of the mothers initiated breastfeeding while $45.7 \%$ had exclusive breastfeeding for at least 6 months, with no significant differences in the initiation or 6-month exclusive breastfeeding by working status ( $\mathrm{p}=0.716$ and $\mathrm{p}=1.000$, respectively) (Data are not tabulated). 
Table 2: Knowledge and its source about breastfeeding among the study participants by working status

\begin{tabular}{|c|c|c|c|c|c|}
\hline Variables & $\begin{array}{c}\text { No \# } \\
\text { (Working/Non- } \\
\text { working) }\end{array}$ & Working & $\begin{array}{c}\text { Non- } \\
\text { working }\end{array}$ & Total & p-value\#\# \\
\hline \begin{tabular}{|l|l|} 
1-Tried to gather information \\
about breastfeeding
\end{tabular} & $(136 / 140)$ & & & & \\
\hline No & & $31(22.8 \%)$ & $47(33.6 \%)$ & $78(28.3 \%)$ & $<0.05 *$ \\
\hline Yes & & $105(77.2 \%)$ & $93(66.4 \%)$ & $198(71.7 \%)$ & \\
\hline \begin{tabular}{|l|l|}
$\begin{array}{l}\text { 2-Received health education about } \\
\text { breastfeeding from any sources }\end{array}$ \\
\end{tabular} & $(136 / 142)$ & & & & \\
\hline No & & $37(27.2 \%)$ & $25(17.6 \%)$ & $62(22.3 \%)$ & 0.055 \\
\hline Yes & & $99(72.8 \%)$ & $117(82.4 \%)$ & $216(77.7 \%)$ & \\
\hline $\begin{array}{l}\text { 3-Received health education about } \\
\text { breastfeeding in hospital }\end{array}$ & $(135 / 143)$ & & & & \\
\hline No & & $57(42.2 \%)$ & $27(18.9 \%)$ & $84(30.2 \%)$ & $<0.001 * *$ \\
\hline Yes & & $78(57.8 \%)$ & $116(81.1 \%)$ & $194(69.8 \%$ & \\
\hline 4-Sources of knowledge of breastfeeding & $(136 / 144)$ & & & & \\
\hline Non-healthcare workers & & $54(39.7 \%)$ & $68(47.2 \%)$ & $122(43.6 \%)$ & 0.205 \\
\hline Healthcare workers & & $82(60.3 \%)$ & $76(52.8 \%)$ & $158(56.4 \%$ & \\
\hline 5-Infant feeding message by gynecologist & $(136 / 143)$ & & & & \\
\hline Breastfeeding only & & $92(67.6 \%)$ & $78(54.5 \%)$ & $170(60.9 \%)$ & 0.070 \\
\hline Artificial only or mixed & & $12(8.8 \%)$ & $21(14.7 \%)$ & $33(11.8 \%)$ & \\
\hline Do not know/not discussed & & $32(23.5 \%)$ & $44(30.8 \%)$ & $76(27.2 \%)$ & \\
\hline 6-Infant feeding message by pediatrician & $(136 / 143)$ & & & & \\
\hline Breastfeeding only & & $86(63.2 \%)$ & $64(44.8 \%)$ & $150(53.8 \%$ & $<0.05 *$ \\
\hline Artificial only or mixed & & $23(16.9 \%)$ & $29(20.3 \%)$ & $52(18.6 \%)$ & \\
\hline Do not know/not discussed & & $27(19.9 \%)$ & $50(35.0 \%)$ & $77(27.6 \%)$ & \\
\hline $\begin{array}{l}\text { 7-Infant feeding message by other } \\
\text { healthcare providers }\end{array}$ & $(136 / 143)$ & & & & \\
\hline Breastfeeding only & & $82(60.3 \%)$ & $83(58.0 \%)$ & $165(59.1 \%$ & 0.898 \\
\hline Artificial only or mixed & & $15(11.0 \%)$ & $18(12.6 \%)$ & $33(11.8 \%)$ & \\
\hline Do not know/not discussed & & $39(28.7 \%)$ & $42(29.4 \%)$ & $81(29.0 \%)$ & \\
\hline $\begin{array}{l}\text { 8-Own opinion about best method } \\
\text { for infant feeding }\end{array}$ & $(136 / 143)$ & & & & \\
\hline Breast feeding only & & $71(52.2 \%)$ & $73(51.0 \%)$ & $144(51.6 \%$ & 0.964 \\
\hline Mixed & & $63(46.3 \%)$ & $68(47.6 \%)$ & $131(47.0 \%)$ & \\
\hline Artificial only & & $2(1.5 \%)$ & $2(1.4 \%)$ & $4(1.4 \%)$ & \\
\hline
\end{tabular}

\# All questions except number four has 1 to 4 missing responses from the study participants.

\#\# p-value was calculated using Chi-square or Fisher's exact tests, as appropriate

$*$ : Significant $\quad * *$ : Highly significant 
Table 2 showed that the majority $(71.7 \%)$ of mothers tried to gather information about breastfeeding. Approximately $77.7 \%$ of them had already received health education about breastfeeding from multiple sources; including healthcare workers (56.4\%) and non-healthcare workers (43.6\%). The mothers were roughly split regarding the best method for infant feeding, which were exclusive breastfeeding in $51.6 \%$ and mixed breast/artificial feeding in $47.0 \%$. Compared with non-working mothers, working mothers tried to gather information about breastfeeding $(77.2 \%$ versus $66.4 \%, \mathrm{p}<0.05)$ received it in hospital health education $(57.8 \%$ versus $81.1 \%$, $\mathrm{p}<0.001)$, and got exclusive breastfeeding message by pediatricians $(63.2 \%$ versus $44.8 \%, \mathrm{p}<0.05)$.

Table 3: Awareness of breastfeeding benefits and duration among the study participants.

\begin{tabular}{|l|c|c|c|c|c|}
\hline & $\begin{array}{c}\text { Strongly } \\
\text { disagree } \\
\text { No \% }\end{array}$ & $\begin{array}{c}\text { Disagree } \\
\text { No \% }\end{array}$ & $\begin{array}{c}\text { Neutral } \\
\text { No \% }\end{array}$ & $\begin{array}{c}\text { Agree } \\
\text { No \% }\end{array}$ & $\begin{array}{c}\text { Strongly } \\
\text { agree } \\
\text { No }\end{array}$ \\
\hline $\begin{array}{l}\text { Artificial feeding is same as } \\
\text { breastfeeding\# }\end{array}$ & $149(53.2 \%)$ & $88(31.4 \%)$ & $24(8.6 \%)$ & $16(5.7 \%)$ & $3(1.1 \%)$ \\
\hline $\begin{array}{l}\text { Breastfed infant is less } \\
\text { liable to ear infection }\end{array}$ & $\begin{array}{c}20 \\
(7.1 \%)\end{array}$ & $15(5.4 \%)$ & $\begin{array}{c}39 \\
(13.9 \%)\end{array}$ & $\begin{array}{c}119 \\
(42.5 \%)\end{array}$ & $87(31.1 \%)$ \\
\hline $\begin{array}{l}\text { Breastfed infant is less } \\
\text { liable to chest infection }\end{array}$ & $\begin{array}{c}14 \\
(5.0 \%)\end{array}$ & $15(5.4 \%)$ & $\begin{array}{c}48 \\
(17.1 \%)\end{array}$ & $\begin{array}{c}128 \\
(45.7 \%)\end{array}$ & $75(26.8 \%)$ \\
\hline $\begin{array}{l}\text { Breastfed infant is less } \\
\text { liable to diarrheal disease }\end{array}$ & $\begin{array}{c}15 \\
(5.4 \%)\end{array}$ & $17(6.1 \%)$ & $\begin{array}{c}62 \\
(22.1 \%)\end{array}$ & $\begin{array}{c}115 \\
(41.1 \%)\end{array}$ & $71(25.4 \%)$ \\
\hline $\begin{array}{l}\text { Breastfeeding should } \\
\text { continue for 6 months }\end{array}$ & $\begin{array}{c}16 \\
(5.7 \%)\end{array}$ & $28(10.0 \%)$ & $\begin{array}{c}52 \\
(18.6 \%)\end{array}$ & $\begin{array}{c}101 \\
(36.1 \%)\end{array}$ & $83(29.6 \%)$ \\
\hline $\begin{array}{l}\text { Breastfeeding protects } \\
\text { against obesity }\end{array}$ & $\begin{array}{l}13 \\
(4.6 \%)\end{array}$ & $21(7.5 \%)$ & $\begin{array}{c}67 \\
(23.9 \%)\end{array}$ & $\begin{array}{c}111 \\
(39.6 \%)\end{array}$ & $68(24.3 \%)$ \\
\hline $\begin{array}{l}\text { Breastfeeding causes social } \\
\text { bond between mother and } \\
\text { baby }\end{array}$ & $\begin{array}{l}18 \\
(6.5 \%)\end{array}$ & $3(1.1 \%)$ & $18(6.5 \%)$ & $\begin{array}{c}81 \\
(29.2 \%)\end{array}$ & $(56.7 \%)$ \\
\hline $\begin{array}{l}\text { Breastfeeding protects } \\
\text { against post-natal } \\
\text { depression }\end{array}$ & $\begin{array}{l}20 \\
(7.2 \%)\end{array}$ & $14(5.0 \%)$ & $\begin{array}{c}66 \\
(23.7 \%)\end{array}$ & $\begin{array}{c}96 \\
(34.4 \%)\end{array}$ & $83(29.7 \%)$ \\
\hline
\end{tabular}

\#The first question was negatively stated. 
Table 3 showed that the items that received high awareness (Agree or Strongly agree) level included the facts that breastfeeding increase mother-baby bond (85.9\%) and breastfeeding is better than artificial feeding $(84.6 \%)$. These were followed by breastfeeding protects against ear infection (73.6\%), chest infection $(72.5 \%)$, diarrheal diseases $(66.4 \%)$, breastfeeding should continue for 6 months $(65.7 \%)$, breastfeeding protects against post-natal depression $(64.2 \%)$ and against obesity $(63.9 \%)$.

None of the above awareness items were significantly different between working and non-working mothers. Using the score of all 8 questions together, the overall awareness of breastfeeding benefits and duration was $78.1 \%$, with no significant difference between working and non-working mothers $(79.3 \%$ versus $76.9 \%, \mathrm{p}=0.195$ ) (Data are not tabulated). 
Table 4: Causes behind stopping breastfeeding ( BF) by working status as reported by studied mothers.

\begin{tabular}{|c|c|c|c|c|}
\hline & $\begin{array}{c}\text { Working } \\
\text { No }=136 \\
(48.6 \%) \\
\text { No \% }\end{array}$ & $\begin{array}{c}\text { Non-working } \\
\text { No }=144 \\
(51.4 \%) \\
\text { No \% } \\
\end{array}$ & $\begin{array}{c}\text { Total } \\
\text { No }=280 \\
(100 \%) \\
\text { No \% }\end{array}$ & $\underset{\text { value\# }}{\mathbf{p}}$ \\
\hline My baby was sick & $90(66.7 \%)$ & $96(73.8 \%)$ & $186(70.2 \%)$ & 0.202 \\
\hline $\begin{array}{l}\text { I thought I did not have enough } \\
\text { milk }\end{array}$ & $85(62.5 \%)$ & $72(54.5 \%)$ & $157(58.6 \%)$ & 0.186 \\
\hline $\begin{array}{l}\text { I was advised not to give } \mathrm{BF} \\
\text { because of my health }\end{array}$ & $107(78.7 \%)$ & $103(78.0 \%)$ & $210(78.4 \%)$ & 0.898 \\
\hline I was sick & $113(83.1 \%)$ & $104(79.4 \%)$ & $217(81.3 \%)$ & 0.439 \\
\hline I think artificial feeding is better & $28(20.6 \%)$ & $32(24.2 \%)$ & $60(22.4 \%)$ & 0.473 \\
\hline $\begin{array}{l}\text { I think BF is difficult and } \\
\text { inconvenient }\end{array}$ & $33(24.3 \%)$ & $37(28.0 \%)$ & $70(26.1 \%)$ & 0.483 \\
\hline I tried BF before and failed & $69(50.7 \%)$ & $68(51.5 \%)$ & $137(51.1 \%)$ & 0.898 \\
\hline I wanted to reduce my weight & $50(36.8 \%)$ & $48(36.1 \%)$ & $98(36.4 \%)$ & 0.909 \\
\hline I wanted to take my usual diet & $56(41.2 \%)$ & $51(38.6 \%)$ & $107(39.9 \%)$ & 0.671 \\
\hline I had a lot of home duties & $54(39.7 \%)$ & $55(41.7 \%)$ & $109(40.7 \%)$ & 0.744 \\
\hline $\begin{array}{l}\text { I planned to return to work or } \\
\text { study }\end{array}$ & $97(71.9 \%)$ & $74(56.1 \%)$ & $171(64.0 \%)$ & $<0.05 *$ \\
\hline I wanted to retain my body & $63(46.3 \%)$ & $59(44.7 \%)$ & $122(45.5 \%)$ & 0.789 \\
\hline My husband refused $B F$ & $21(15.6 \%)$ & $36(27.3 \%)$ & $57(21.3 \%)$ & $<0.05 *$ \\
\hline My mother in law refused BF & $15(11.0 \%)$ & $11(8.4 \%)$ & $26(9.7 \%)$ & 0.468 \\
\hline $\begin{array}{l}\text { I wanted to use contraception that } \\
\text { affect } \mathrm{BF}\end{array}$ & $66(48.5 \%)$ & $75(56.8 \%)$ & $141(52.6 \%)$ & 0.174 \\
\hline I fail to express breast milk & $65(47.8 \%)$ & $65(49.6 \%)$ & $130(48.7 \%)$ & 0.766 \\
\hline $\begin{array}{l}\text { I did not find support from my } \\
\text { work }\end{array}$ & $84(62.2 \%)$ & $65(49.6 \%)$ & $149(56.0 \%)$ & $<0.05 *$ \\
\hline
\end{tabular}

\#: p value was calculated using Chi-square or Fisher's exact tests, as appropriate. *: Significant 
Several potential causes behind stopping breastfeeding were examined as shown in Table 4 . The causes that were recognized by more than half of the mothers included; sick mother (81.3\%), advice to the mother not to give breastfeeding because of her health $(78.4 \%)$, sick baby $(70.2 \%)$, plans to return to work or study (64.0\%), thoughts that the mother does not have enough milk (58.6\%), lack of support from the mother's work $(56.0 \%)$, the mother wants to use contraception that affect breastfeeding (52.6\%), and previous experience of failed breastfeeding after initial trial $(51.1 \%)$. On the other hand, the causes that received little recognition by the mothers included; artificial feeding is better than breastfeeding (22.4\%), husband refused breastfeeding $(21.3 \%)$, and mother in law refused breastfeeding $(9.7 \%)$. Only few recognized causes were differentially reported by working and non-working mothers. For example, plans to return to work or study and lack of support from the mother.

Table 5: Factors associated with practicing exclusive breastfeeding ( BF) using univariate and multivariate logistic regression $(\mathrm{No}=280)$.

\begin{tabular}{|l|l|l|l|l|}
\hline \multirow{2}{*}{} & \multicolumn{2}{|c|}{ Univariate analysis } & \multicolumn{2}{c|}{ Multivariate analysis } \\
\cline { 2 - 5 } & OR (95\% CI) & p value & OR (95\% CI) & $\begin{array}{c}\text { p } \\
\text { value }\end{array}$ \\
\hline Working mothers & $0.99(0.62-1.59)$ & 0.967 & $1.05(0.64-1.73)$ & 0.848 \\
\hline Age (reference $>35$ years) & & & & \\
\hline 18-25 years & $1.32(0.71-2.43)$ & 0.382 & & \\
\hline 26-35 years & $0.80(0.43-1.47)$ & 0.468 & & \\
\hline Nationality (Saudi vs non-Saudi) & $3.24(1.42-7.41)$ & 0.005 & $3.18(1.35-7.50)$ & $<\mathbf{0 . 0 5 *}$ \\
\hline Education (University vs lower) & $0.92(0.57-1.51)$ & 0.748 & & \\
\hline Gravidity ( $\geq 3$ vs $\leq 2)$ & $0.69(0.43-1.12)$ & 0.136 & & \\
\hline Parity $(\geq 3$ vs $\leq 2)$ & $0.75(0.46-1.21)$ & 0.235 & & \\
\hline Mode of delivery (1) & $1.14(0.62-2.10)$ & 0.683 & & \\
\hline Tried to gather information about BF & $1.23(0.73-2.09)$ & 0.438 & & \\
\hline Received health education about BF & & & & \\
\hline From any source & $0.44(0.25-0.79)$ & 0.006 & $2.23(1.22-4.07)$ & $<\mathbf{0 . 0 5 *}$ \\
\hline In hospital & $0.64(0.38-1.06)$ & 0.083 & & \\
\hline Sources of knowledge of breastfeeding & $0.66(0.41-1.05)$ & 0.081 & & \\
\hline Overall BF awareness score & $1.22(0.27-5.55)$ & 0.795 & & \\
\hline
\end{tabular}

OR: odds ratio; $95 \%$ CI: $95 \%$ confidence interval;

*: Significant 
The outcome was breastfeeding for at least 6 months. Working status was forced in the model. Multivariate analysis was done backward stepwise logistic regression

Table 5 shows the odds ratios (ORs) of the factors associated with practicing exclusive breastfeeding for at least 6 months using univariate and multivariate logistic regression. Working status (working versus non-working) was not a significant predictor for exclusive breastfeeding using univariate $(\mathrm{OR}=$ $0.99,95 \% \mathrm{CI}=0.62-1.59, \mathrm{p}=0.967$ ) nor multivariate analysis $(\mathrm{OR}=1.05,95 \%$ $\mathrm{CI}=0.64-1.73, \mathrm{p}=0.848)$. On the other hand, the factors that were significant predictors of exclusive breastfeeding irrespective of working status and other relevant factors included : Saudi nationality $(\mathrm{OR}=3.18,95 \% \mathrm{CI}=1.35$ $7.50, \mathrm{p}=0.008$ ) and receiving health education about breastfeeding from any source $(\mathrm{OR}=2.23,95 \% \mathrm{CI}=1.22-4.07$, $\mathrm{p}=0.009)$

\section{Discussion}

The current study showed that almost all $(97.5 \%)$ of the mothers initiated breastfeeding while less than half $(45.7 \%)$ had exclusive breastfeeding for at least 6 months (nontabulated data). The higher initiation but low exclusive breastfeeding at 6-month have been reported before in several studies in Saudi Arabia (El Mouzan et al., 2009 and Al Juaid et al., 2014). For example, a recent review of 17 Saudi cross-sectional studies published between 1979 and 2011 showed that the rate of initiation of breastfeeding ranged between $90 \%$ and $99 \%$ while the rate of exclusive breastfeeding for at least 6 months ranged between approximately $1 \%$ and $43 \%$ (Al Juaid et al., 2014). The rate of exclusive breastfeeding at 6 months in the current study $(45.7 \%)$ is considered high and probably challenging the reports that suggested decline of breastfeeding duration in Saudi Arabia over the last 2 decades (Al Juaid et al., 2014) . However, comparisons of the current rate with previous rates is a difficult and may be unfair process. For example, only few of the studies included in the Al Juaid et al. review (2014) used the WHO definition for exclusive breastfeeding. Additionally, the age of the infants/children in these studies was very variable ranging between 3 months and 24 months. Finally, the 
current study included mothers who attended the $\mathrm{MCH}$ clinic services in two major hospitals; one of them is internationally recognized "Baby Friendly Hospital", so they might have been exposed to repeated messages that promote the continuation of exclusive breastfeeding. This last explanation is probably supported by the fact that approximately $70 \%$ of the mothers in the current study received in-hospital health education about breastfeeding (Table 2). Interestingly, the current rates of exclusive breastfeeding generally match WHO global data which showed that $43 \%$ of infants in their first 6 months of life were exclusively breastfed (WHO, 2016).

We are reporting a high level of awareness about breastfeeding in the current study. For example, $78 \%$ of the mothers were aware of breastfeeding and its benefit (Table 3). This finding may be better than those reported in previous studies (Alwelaie et al., 2010; Al-Binali, 2012 and Shommo and AlShubrumi, 2014). The higher awareness of our participants may reflect the fact that more than three-quarters of them reported receiving health education about breastfeeding, predominantly in the hospital (Table 2). This is considered much higher than reported in previous studies that showed rates of $51 \%$ in the Southwestern region (Al-Binali, 2012), $55 \%$ in the Central region (Alwelaie et al., 2010), and 60\% in the Northwestern region (Shommo and Al-Shubrumi, 2014). Additionally, $70 \%$ of the mothers in the current study received hospital health education and the role of healthcare provider of different specialties was noticeable, which was more than seen in other studies where relatives and media constituted a major source (Alwelaie et al., 2010). This again may be the result of establishing breastfeeding friendly environment in our hospitals, mainly through the establishment of BFHI program.

Although working and non-working mothers in the current study showed clear difference as regards demographics and obstetric history (Table1), unexpectedly, there were no significant differences in the Knowledge and Attitude of breastfeeding (Table 2). Moreover, the rate of initiation of breastfeeding and exclusive breastfeeding for at least 6 months were similar in both groups. 
This was evident using either univariate or multivariate analysis (Table5). Local data examining the impact of working status on the mother's awareness and practices of breastfeeding in Saudi Arabia are generally limited and probably conflicting (Kordy et al., 1992; Al- Hreashy et al., 2008; AlMadani et al., 2010; and El-Gilany et al., 2011). For example, only $5 \%$ to $15 \%$ of the mothers in the previous studies were working (Al-Madani et al., 2010 and El-Gilany et al., 2011) compared to almost half of the mothers in the current study (Table 1). Additionally, the majority of studies showed negative association between working status and the duration of and/or the exclusiveness of breastfeeding (Al- Hreashy et al., 2008; Al-Madani et al., 2010; and ElGilany et al., 2011). Some studies failed to show any association (Kordy et al.,1992). The lack of work impact on the awareness of breastfeeding may reflect the fact that the majority of the working and non-working mothers in the current study received health education about breastfeeding (Table 2 ). This health education was more of a personal initiative in working mother who tried more to gather information about breastfeeding, while in nonworking mothers health education was received more in the hospital (Table 2 ). Finally, the lack of work impact on the practices of breastfeeding in the current study (Table 5) may reflect the cooperative work regulation in Saudi Arabia that grants Saudi women paid maternity leave for 70 days and unpaid leave thereafter.

Several causes behind stopping breastfeeding were reported in the current study (Table 4). They were mainly: sick mother, professional advice not to give breastfeeding, sick baby, plans to return to work or study, and not having enough breast milk. In Al Juaid et al. (2014) review of 11 studies that reported causes of early stopping of breastfeeding, insufficient milk was reported by $23 \%$ to $66 \%$ of the mothers and sick mother or baby was reported by $7 \%$ to $30 \%$ of the mothers.

Although the current study is considered the first study to focus on awareness and practices of breastfeeding among working and non-working mothers in Saudi Arabia, using a standard definition of exclusive breastfeeding, in two centers in the 
Eastern region, we acknowledge a number of limitations. Similar to previous studies we used a crosssectional design which cannot prove causation but rather only association. Since the questionnaire depends on selfreported information by the mothers about breastfeeding, recall bias cannot be excluded. Although the study was conducted in two centers in the Eastern region, the findings of this study should be generalized to Saudi Arabia only with caution as the educational and employment levels in this study are much higher than typically seen in Saudi Arabia.

\section{Conclusion}

We are reporting high awareness level about breastfeeding among a group of working and non-working mothers attending $\mathrm{MCH}$ services in two centers in the Eastern region. Almost all mothers initiated breastfeeding but approximately $46 \%$ continued exclusive breastfeeding at 6-month. There were no significant differences as regards awareness and practices of breastfeeding between working and non-working mothers.

\section{Conflict of interest}

The authors declared that no conflicts of interest existed.

\section{Acknowledgement}

The authors would like to acknowledge the health educators who collected the data in the current study.

\section{References}

1. Al-Binali AM (2012): Breastfeeding knowledge, attitude and practice among school teachers in Abha female educational district, southwestern Saudi Arabia. Int Breastfeed J ; 7(1): 10.

2. Al-Hreashy FA, Tamim HM, Al-Baz N, AlKharji NH, Al-Amer A, et al.(2008): Patterns of breastfeeding practice during the first 6 months of life in Saudi Arabia. Saudi Med J; 29(3): 427-31.

3. Al-Madani $\mathbf{M}$, VydelingumV and Lawrence $\mathbf{J}$ (2010): Saudi mothers' expected intentions and attitudes toward breast-feeding. ICAN: Infant, Child, and Adolescent Nutrition; 2(3): 187-98.

4. Al Juaid DA, Binns CW and Giglia RC (2014): Breastfeeding in Saudi Arabia: a review. Int Breastfeed J ;9(1): 1.

5. Alwelaie YA, Alsuhaibani EA, Al-Harthy AM, Radwan RH, Al-Mohammady RG et al.(2010): Breastfeeding knowledge and attitude among Saudi women in Central Saudi Arabia. Saudi Med J; 31(2): 193-98.

6. American Academy of Pediatrics (2012): Policy Statement. Breastfeeding and the Use of Human Milk. Pediatrics ;129(3):827-41.

7. Atabay E, Moreno G, Nandi A, Kranz G, Vincent I, et al (2015): Facilitating working mothers' ability to breastfeed: global trends in guaranteeing breastfeeding breaks at work, 1995-2014. J Hum Lact ;31(1): 81-8.

8. El-Gilany AH, Shady E and Helal R (2011): Exclusive breastfeeding in Al-Hassa, Saudi Arabia. Breastfeed Med ;6(4): 209- 13. 
9. El Mouzan MI, Al Omar AA, Al Salloum AA, Al Herbish AS and Qurachi MM (2009): Trends in infant nutrition in Saudi Arabia: compliance with WHO recommendations. Ann Saudi Med; 29(1): 20- 3.

10. Hirani SA and Karmaliani R (2013): Evidencebased workplace interventions to promote breastfeeding practices among Pakistani working mothers. Women Birth;26(1): 10-6.

11. Iellamo A, Sobel H and Engelhardt K (2015): Working mothers of the World Health Organization Western Pacific offices: lessons and experiences to protect, promote, and support breastfeeding. J Hum Lact ;31(1): 36- 9.

12. International Labour Organization (2016): Labour force participation rate. Key Indicators of the Labour Market database, Ninth edition. Geneva, International Labour Office, 2016. URL: http://www.ilo.org/wcmsp5/groups/ public/---dgreports/---stat/documents/ publication/wcms_498929.pdf (Last accessed March 1, 2017).

13. Johnston ML and Esposito N (2007): Barriers and facilitators for breastfeeding among working women in the United States. J Obstet Gynecol Neonatal Nurs ;36(1): 9-20.

14. Kordy MN, Ibrahim MA, El-Gamal FM and Bahnassy AA(1992): Factors affecting the duration of breastfeeding in a rural population of Saudi Arabia. Asia Pac J Public Health; 6(1): 35-9.

15. Kramer MS, Aboud F, Mironova E, Vanilovich I, Platt RW,et al.(2008): Breastfeeding and child cognitive development: new evidence from a large randomized trial. Arch Gen Psychiatry ;65(5): 578-84.

16. Kramer MS and Kakuma R (2012): Optimal duration of exclusive breastfeeding. Cochrane Database Syst Rev;(8): CD003517.

17. Nabi G and Al-Mendalawi MD (2008): Patterns of breastfeeding practice during the first 6 months of life in Saudi Arabia. Saudi Med J; 29(8): 1208-1210.
18. National Institute of Child Health and Human Development (2009): Breastfeeding. URL: http://www.nichd.nih.gov/health/topics/ Breastfeeding/ (Last accessed March 1, 2017).

19. Ong G, Yap M, Li FL and Choo TB (2005): Impact of working status on breastfeeding in Singapore: evidence from the National Breastfeeding Survey 2001. Eur J Public Health ;15(4): 424-30.

20. Shommo SA and Al-Shubrumi H (2014): Breastfeeding knowledge, attitude and practice among mothers in Hail district, northwestern Saudi Arabia. IOSR-JNHS;3(1): 49-56.

21. UNICEF and WHO (2015): Advocacy Strategy. Breastfeeding Advocacy Initiative. For the best start in life. February 2015 URL: https:// www.unicef.org/nutrition/files/Breastfeeding _ Advocacy_Strategy-2015.pdf (Last accessed March 1, 207).

22. Victira CG, Bahl R, Barros AJ, Franca GV, Horton S, et al. (2016): Breastfeeding in the 21st century: epidemiology, mechanisms, and lifelong effect. Lancet 387;(10017): 475- 90.

23. WHO (2008): Indicators for assessing infant and young child feeding practices : conclusions of a consensus meeting held 6-8 November 2007 in Washington D.C., USA. Part 1: definitions. Geneva: WHO Press; 2008 URL: https://www .unicef.org/nutrition/files/IYCF_ updated_indicators_2008_part_1_definitions. pdf (Last accessed March 1, 2017).

24. WHO (2009): Baby-Friendly Hospital Initiative Revised, updated and expanded for integrated care. Geneva: WHO Press 2009. URL: http://apps.who.int/iris/ bitstream/10665/43593/1/9789241594967_eng. pdf (Last accessed March 1, 2017).

25. WHO (2016): Infant and young child feeding. Fact sheet. Updated September 2016. URL: http://who.int/mediacentre/factsheets/fs342/en/ (Last accessed March 1, 2017). 